April 2, 2001

\title{
Sources of German Unemployment: A Structural Vector Error Correction Analysis ${ }^{1}$
}

\author{
Ralf Brüggemann \\ Institut für Statistik und Ökonometrie \\ Humboldt-Universität zu Berlin \\ Spandauer Str. 1 \\ 10178 Berlin \\ GERMANY \\ Tel.: +49-30-2093-5603 \\ Fax.: +49-30-2093-5712 \\ email: brueggem@wiwi.hu-berlin.de
}

\begin{abstract}
In this paper we analyze the sources of German unemployment within a structural vector error correction model (SVECM) framework. For this purpose, we propose a method to estimate an exactly identified Subset SVECM, which is a SVECM with short run parameter restrictions. A cointegration analysis for the unified Germany reveals a long run relationship between real wages, productivity and unemployment which is interpreted as a wage setting relation. From a Subset VECM we identify meaningful structural shocks and assess their importance for unemployment by impulse response analysis and forecast error variance decompositions. We compare these results to results from a standard SVECM and find that using the Subset VECM reduces estimation uncertainty. In contrast to previous studies for West Germany, we find that unemployment is equally determined by technology, labor supply and labor demand shocks in the long run.
\end{abstract}

Keywords: Unemployment, Subset VECM, Structural VECM, Bootstrap, Cointegration JEL classification: C32, E24

\footnotetext{
${ }^{1}$ I thank Helmut Lütkepohl, Sabine Kröger, Almuth Scholl and Carsten Trenkler for their helpful comments and suggestions. Special thanks to Hans-Martin Krolzig for providing a beta version of PcGets. Financial support by the Deutsche Forschungsgemeinschaft, SFB 373, is gratefully acknowledged.
} 


\section{Introduction}

Persistently high unemployment is one of the major economic problems in Germany. Ever since the mid 70s the unemployment rate has been increasing. While this development has been observed in most European countries, the German reunification in 1990:3 has boosted the unemployment rate to new record levels. This increase has stimulated economists to investigate the sources of unemployment more closely. A particularly interesting question from a macroeconomic point of view is whether unemployment is mainly determined by structural factors such as technology, labor supply, or wage setting shocks or by cyclical such as aggregate demand or labor demand shocks. The answer to this question has, of course, important policy implications. If unemployment is only determined by structural factors, demand side management policies cannot successfully reduce unemployment.

In this paper we try to answer this question by identifying important shocks for the German labor market and assess their importance for unemployment within a structural vector error correction model (SVECM) by impulse response functions (IRF) and forecast error variance decompositions (FEVD). The structural VAR (SVAR) modeling framework has been previously used to analyze the labor market of different countries. Dolado \& Jimeno (1997) investigate the sources of Spanish unemployment using a VAR in first differences. They find that unemployment is explained by a mixture of supply and demand shocks. Jacobson, Vredin \& Warne (1997) use a common trends model to compare the labor markets of Scandinavian countries and conclude that the only common source of unemployment in Denmark, Norway and Sweden is shocks to wage setting. Carstensen \& Hansen (2000) analyze the West German labor market and find that unemployment is equally determined by technology and labor supply shocks in the long run. The present study differs from Carstensen \& Hansen (2000) in two important respects. First, we use a model similar to the one in Jacobson et al. (1997) to derive the identifying assumption, because it implies a smaller set of variables and avoids the somewhat arbitrary concept of a goods market equation. Second, we use data for the unified Germany from the third quarter of 1990 onwards rather than West German data only. Over ten years after German reunification it seems natural to use data for the whole country even though this may imply some extra problems.

This study also differs from previous ones in some methodological aspects: For Maximum Likelihood (ML) estimation of SVECMs, the short run parameters have to be unrestricted (see Breitung (2000) and Amisano \& Giannini (1992)), which often results in imprecise estimates as reflected by wide confidence bands of the IRF. To get more precise estimates, short run parameter restrictions on the basis of statistical procedures may be desirable. In the case of exact identification these short run restrictions can be incorporated because the covariance restrictions result in a nonlinear equation system, which can easily be solved by computer packages. We call the resulting model with additional short run parameter 
restrictions a Subset SVECM model and compare results from the Subset SVECM with results from a standard SVECM.

The paper is structured as follows. In section 2 we present the modeling framework and show how SVECMs can be estimated in the presence of short run parameter restrictions. Section 3 presents a small macroeconomic model of the labor market to motivate the identifying assumptions for the structural analysis. In section 4 we conduct the cointegration analysis before the labor market shocks are identified in section 5, which also contains the impulse response analysis and the FEVD. Section 6 concludes.

\section{Econometric Methodology}

Vector Autoregression (VAR) models have become increasingly popular after Sims's (1980) critique of the simultaneous equation approach. However, the standard VAR is a reduced form model and economic interpretation of the results is often impossible, unless the reduced form VAR is linked to an economic model. If economic theory is used to provide the link between forecast errors and fundamental shocks, we call the resulting model a SVAR. Models of this type have become an important tool in macroeconomics and have been used to analyze the effects of monetary shocks (see Christiano, Eichenbaum \& Evans (1999)), the effects of technology shocks (Galí (1999)) and the effects of fiscal shocks (see Rotemberg \& Woodford (1992)), for example. It is also possible to apply the SVAR technique to vector error correction models (VECM) with cointegrated variables. Such models are called SVECMs. In what follows, we describe the relation between structural and reduced form VAR and VECM more precisely, because it is crucial for the understanding of the SVAR and SVECM method.

The SVAR analysis starts from the reduced form standard VAR(p) model

$$
y_{t}=A_{1} y_{t-1}+\cdots+A_{p} y_{t-p}+\Xi D_{t}+u_{t}
$$

where $y_{t}$ is a $K \times 1$ vector of time series, $D_{t}$ a vector of deterministic terms, and $A_{1}, \ldots, A_{p}$ are $K \times K$ coefficient matrices. $\Xi$ is the coefficient matrix associated with deterministic terms, such as a constant, trend and seasonal dummies. The reduced form disturbance $u_{t}$ is a $K \times 1$ unobservable zero mean white noise process with covariance matrix $\Sigma_{u}$. Typically, researchers are interested in the effects of the fundamental shocks on the system variables $y_{t}$. These shocks are expressed in terms of the structural form

$$
\bar{A}_{0} y_{t}=\bar{A}_{1} y_{t-1}+\cdots+\bar{A}_{p} y_{t-p}+\bar{\Xi} D_{t}+\varepsilon_{t},
$$

where the $K \times 1$ vector $\varepsilon_{t}$ contains the unobservable structural disturbances and has the covariance matrix $\Sigma_{\varepsilon}$. Thus, to compute the responses to the economic shocks $\varepsilon_{t}$, we have to link the forecast errors $u_{t}$ to the structural shocks $\varepsilon_{t}$. Premultiplying the system (2.2) by 
$\bar{A}_{0}{ }^{-1}$ gives the reduced form $(2.1)$ with $A_{1}=\bar{A}_{0}{ }^{-1} \bar{A}_{1}, \ldots, A_{p}=\bar{A}_{0}{ }^{-1} \bar{A}_{p}, \Xi=\bar{A}_{0}{ }^{-1} \bar{\Xi}$ and

$$
u_{t}=\bar{A}_{0}^{-1} \varepsilon_{t},
$$

which relates the reduced form disturbance $u_{t}$ to the underlying structural shock. Note that relation (2.3) also holds if variables in $y_{t}$ are cointegrated. Then, the VAR(p) model (2.1) has a vector error correction representation denoted as $\operatorname{VECM}(\mathrm{p})$

$$
\Delta y_{t}=\Pi y_{t-1}+\Gamma_{1} \Delta y_{t-1}+\cdots+\Gamma_{p-1} \Delta y_{t-p+1}+\Xi^{+} D_{t}+u_{t}
$$

which is obtained by subtracting $y_{t-1}$ from both sides of (2.1) and rearranging terms (see Lütkepohl (2001) for precise formulas). Equivalently, (2.2) can be expressed as a structural $\operatorname{VECM}(\mathrm{p})$ and hence (2.3) also holds for VECM models. In cointegrated models $\Pi$ has reduced rank $r=r k(\Pi)<K$ and can be decomposed as $\Pi=\alpha \beta^{\prime}$, where $\alpha$ and $\beta$ are $K \times r$ matrices containing the loading coefficients and the cointegration vectors, respectively.

To analyze the effects of the underlying structural shocks, we need to recover the $K^{2}$ elements of ${\overline{A_{0}}}^{-1}$. For this purpose we need identifying restrictions coming from economic theory. To see this more clearly we use the relation (2.3) to write

$$
\Sigma_{u}=E\left[u_{t} u_{t}^{\prime}\right]={\overline{A_{0}}}^{-1} E\left[\varepsilon_{t} \varepsilon_{t}^{\prime}\right]\left({\overline{A_{0}}}^{-1}\right)^{\prime}={\overline{A_{0}}}^{-1} \Sigma_{\varepsilon}\left({\overline{A_{0}}}^{-1}\right)^{\prime}
$$

and use the standard assumption that the structural shocks are uncorrelated and have unit variances, i.e. $\Sigma_{\varepsilon}=I_{K}$, to get

$$
\Sigma_{u}={\overline{A_{0}}}^{-1}\left({\overline{A_{0}}}^{-1}\right)^{\prime} .
$$

The symmetry of $\Sigma_{u}$ and the normalization of the structural variances impose $K(K+1) / 2$ nonlinear restrictions on the $K^{2}$ parameters of ${\overline{A_{0}}}^{-1}$. To exactly identify the elements of ${\overline{A_{0}}}^{-1}$ we need to impose $K(K-1) / 2$ additional, linearly independent restrictions. Since economic theory has more to say about the long run, we prefer to impose long run restrictions rather than contemporaneous restrictions. From Granger's representation theorem (see Johansen (1995)) we know that the VECM from (2.4) can be represented as a Vector Moving Average (VMA) process

$$
y_{t}=C(1) \sum_{i=1}^{t}\left(u_{i}+\Xi D_{i}\right)+C_{1}(L)\left(u_{t}+\Xi D_{t}\right)+y_{0},
$$

where $y_{0}$ depends on the initial conditions and $C(1)$ is the total impact matrix computed as $C(1)=\beta_{\perp}\left(\alpha_{\perp}^{\prime}\left(I_{K}-\sum_{i=1}^{p-1} \Gamma_{i}\right) \beta_{\perp}\right)^{-1} \alpha_{\perp}^{\prime}$. $\beta_{\perp}$ and $\alpha_{\perp}$ represent the orthogonal complements of $\beta$ and $\alpha$, respectively. Note that $C(1)$ has reduced rank $r k(C(1))=K-r$. From (2.7) it follows that the long run effects of structural shocks $\varepsilon_{t}$ can be written as

$$
C(1) \bar{A}_{0}^{-1}
$$


Long run zero restrictions as implied by economic theory can now be imposed easily by setting elements of (2.8) to zero. The common trends literature (see for example King, Plosser, Stock \& Watson (1991)) distinguishes between permanent and transitory effects. In particular, we know that in a system with $r$ cointegration relations, only $k=K-r$ shocks can have permanent effects. To exactly identify permanent shocks we need $k(k-1) / 2$ additional restrictions. Similarly, $r(r-1) / 2$ restrictions identify the transitory shocks.

Structural VECMs are usually estimated by ML. The estimation procedure is described in Amisano \& Giannini (1992) and software packages, such as Malcom by Mosconi (1998), are available to solve the computationally demanding problem. ML estimation of structural VECMs does not allow additional restrictions on the short run dynamics, because the likelihood function is concentrated with respect to $\alpha, \Gamma_{1}, \ldots, \Gamma_{p-1}$. However, short run restrictions may be desirable to improve the estimation precision, given the large number of parameters in a VECM. We use such a restricted Subset VECM to recover the structural shocks. This is possible if the model is exactly identified. In that case (2.6) and (2.8) formulate a nonlinear equation system that can be solved for the elements of $\bar{A}_{0}^{-1}$ even with restricted short run dynamics. Therefore, this method allows to include contemporaneous as well as long run restrictions.

The Subset SVECM analysis is structured as follows: First, we determine the cointegration rank of the system of interest and possibly impose overidentifying restrictions on the cointegrating vectors using the ML method proposed by Johansen (1995). Then, we fix the estimated cointegration vector and use statistical procedures as proposed by Brüggemann \& Lütkepohl (2000) to derive a Subset VECM model. In a third step, we impose exactly identifying restrictions to compute the contemporaneous impact matrix ${\overline{A_{0}}}^{-1}$ by solving the nonlinear equation system. ${ }^{2}$ Using this estimate it is possible to compute impulse responses and FEVD for the identified system. The estimation of Subset SVECMs is fast and allows the computation of bootstrap confidence bands for the IRF. In the remainder of the paper, we use the Subset SVECM technique to analyze the German labor market.

\section{A Small Labor Market Model}

In this section we briefly describe a simple macroeconomic model of the labor market, which is very similar to the one used by Jacobson et al. (1997). The model is the basis for the identifying restrictions imposed in the structural analysis of Section 5 . It consists of a production function, a labor demand relation, a labor supply, and a wage setting relation. All variables are expressed in natural logarithms.

The production function relates output $\left(g d p_{t}\right)$ to employment $e_{t}$

$$
g d p_{t}=\rho e_{t}+\theta_{1, t}
$$

\footnotetext{
${ }^{2}$ Solving the nonlinear system is a simple numerical problem for computer packages as NLSYS for GAUSS.
} 
where $\rho$ measures the return to scale. $\theta_{1, t}$ is a stochastic technology trend that follows a random walk

$$
\theta_{1, t}=\theta_{1, t-1}+\varepsilon_{g d p, t}
$$

and $\varepsilon_{g d p, t}$ is the pure technology shock. Labor demand relates employment to output and real wages:

$$
e_{t}=\lambda g d p_{t}-\eta(w-p)_{t}+\theta_{2, t}
$$

with

$$
\theta_{2, t}=\phi_{d} \theta_{2, t-1}+\varepsilon_{d, t}
$$

If $\left|\phi_{d}\right|<1$ the labor demand is stationary. In that case the pure labor demand innovation $\varepsilon_{d, t}$ has only temporary effects on employment. Jacobson et al. (1997) do not allow for a possible nonstationary labor demand in their model and assume a priori $\phi_{d}=0$. This restrictions implies that the labor demand shock has no long run effects. Clearly, this is a very strong assumption. Since we are not willing to make this assumption at this stage of the analysis, we use the slightly more general form of the model. The cointegration analysis in Section 4 will show, whether labor demand is stationary.

Labor force $l_{t}$ is assumed to be related to real wages according to

$$
l_{t}=\pi(w-p)_{t}+\theta_{3, t} .
$$

The exogenous labor supply trend $\theta_{3, t}$ follows a random walk

$$
\theta_{3, t}=\theta_{3, t-1}+\varepsilon_{s, t}
$$

where $\varepsilon_{s, t}$ is the underlying labor supply shock. Finally, we have the wage setting relation

$$
(w-p)_{t}=\delta\left(g d p_{t}-e_{t}\right)-\gamma\left(l_{t}-e_{t}\right)+\theta_{4, t}
$$

stating that real wages are a function of productivity and unemployment. The wage setting trend $\theta_{4, t}$ can be stationary or nonstationary depending on $\phi_{w}$ in

$$
\theta_{4, t}=\phi_{w} \theta_{4, t-1}+\varepsilon_{w, t}
$$

If $\left|\phi_{w}\right|<1$, the wage setting trend is stationary. Again, we use results from the empirical analysis to determine whether wage setting is stationary. To close the model we assume that $\varepsilon_{g d p, t}, \varepsilon_{d, t}, \varepsilon_{s, t}$, and $\varepsilon_{w, t}$ are identically and independently distributed with zero mean and variances $\sigma_{g d p}^{2}, \sigma_{d}^{2}, \sigma_{s}^{2}$, and $\sigma_{w}^{2}$, respectively. The solution of the model (3.1) - (3.4) in 
terms of the variables used in the empirical analysis is given by

$$
\begin{gathered}
{\left[\begin{array}{c}
g d p_{t}-e_{t} \\
e_{t} \\
l_{t}-e_{t} \\
(w-p)_{t}
\end{array}\right]=\psi\left[\begin{array}{c}
(1-\lambda)(1+\gamma \pi)+\eta \gamma \\
\lambda(1+\gamma \pi)-\eta \delta \\
\eta \delta-\lambda+(1-\lambda) \pi \delta \\
\lambda \gamma+\delta(1-\lambda)
\end{array}\right] \theta_{1, t}+\psi\left[\begin{array}{c}
(\rho-1)(1+\gamma \pi) \\
1+\gamma \pi \\
(\rho-1) \delta \pi-1 \\
\gamma-\delta(1-\rho)
\end{array}\right] \theta_{2, t}} \\
+\psi\left[\begin{array}{c}
(\rho-1) \eta \gamma \\
\eta \gamma \\
1-\rho \lambda+(\rho-1) \delta \eta \\
(\rho \lambda-1) \gamma
\end{array}\right] \theta_{3, t}+\psi\left[\begin{array}{c}
\eta(1-\rho) \\
-\eta \\
\eta+(1-\rho \lambda) \pi \\
1-\rho \lambda
\end{array}\right] \theta_{4, t}
\end{gathered}
$$

with

$$
\psi=\frac{1}{(1-\rho \lambda)(1+\gamma \pi)+\eta \gamma+(\rho-1) \eta \delta} .
$$

From (3.5) we see that productivity, employment, unemployment and real wages are driven by two random walks in productivity and labor supply. As explained above, the labor demand and the wage setting component can be stationary or nonstationary. In terms of the common trends literature, there are at least two and at most 4 common trends in this model. This implies at most two cointegration relations: a labor demand relation and a wage setting relation. We now turn to the empirical analysis.

\section{Cointegration Analysis of the German Labor Market}

In this paper we use quarterly, seasonally unadjusted data for the unified Germany constructed from the Deutsches Institut für Wirtschaftsforschung (DIW) database for the period from 1970 until 1998. Prior to 1970 the German labor market was characterized by full employment, which we see as a different economic regime. Accordingly, we choose the estimation start date 1970:1, because starting in the early 70s unemployment became a major problem. All data refer to West Germany until 1990:2 and to unified Germany afterwards.

In the empirical analysis we use four series: hourly productivity $g d p_{t}-e_{t}$, employment $e_{t}$, the unemployment rate $u_{t} \approx l_{t}-e_{t}$ and hourly real wages $w_{t}-p_{t}$. Appendix A gives a detailed description on how the series have been constructed. The vector we use in the cointegration analysis therefore includes

$$
y_{t}=\left[\left(g d p_{t}-e_{t}\right), e_{t}, u_{t},\left(w_{t}-p_{t}\right)\right]^{\prime}
$$

The time series $y_{t}$ are shown in Figure 1. The productivity and the employment series exhibit are clear level shift due to the German reunification that took place in the third quarter of 1990. As expected the productivity series shows a considerable downward shift, while employment (measured in hours) increases. In the unemployment series we observe 

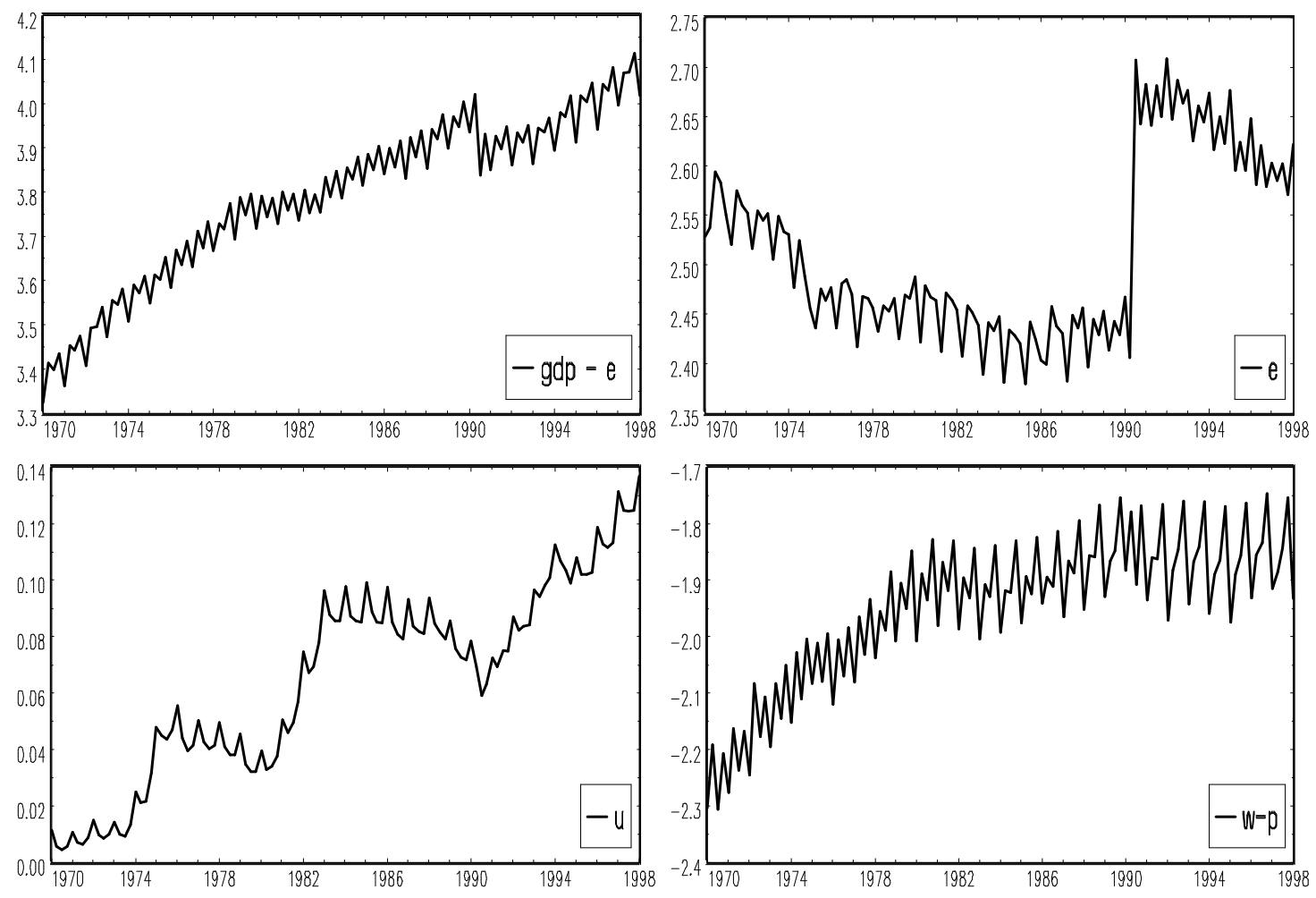

Figure 1. Labor Market Time Series Analyzed

a strong upward trend starting in 1990. There is also a level shift, which is not as obvious as in the other series. The hourly real wage series has a level shift as well. It is however comparably small, because the increase in hours of employment is partly offset by decreasing nominal wages.

Before we continue with the system analysis we investigate the integration properties of the four time series. Clearly, we have to account for the level shifts and do so by applying two types of unit root tests suggested by Perron (1989) and Lanne, Lütkepohl \& Saikkonen (1999). For the Perron test, the third column of Table 1 reports the deterministic terms used in an auxiliary regression. We use the residuals from that regression and apply an augmented Dickey-Fuller test (ADF) with the number of lags indicated by the second column of Table 1. We choose the model A from Perron (1989) for productivity, employment and real wages, as this model allows a level shift. For the unemployment series, the model $\mathrm{C}$ which allows for a break in the trend and in the constant seems to be more appropriate. For some of the first differences, we have applied the standard ADF test. In these cases, the third column reports the deterministic terms included in the Dickey-Fuller regression.

In addition, we also use unit root tests that allow a more flexible shift to the new level of the series. The basic idea of the tests proposed by Lanne et al. (1999) is to estimate the deterministic part including a shift function in a first step, adjust the series for these terms and apply a Dickey-Fuller type test to the adjusted series. In this study we use the test 
Table 1. Unit Root Tests

\begin{tabular}{cccll|ccc}
\hline \hline \multicolumn{4}{c}{ Perron / ADF Tests } & \multicolumn{3}{c}{$\tau$ Tests } \\
\hline var. & lags & det. & statistic & $5 \%$ crit. & det. & $\tau$ & $5 \%$ \\
\hline$g d p-e$ & 4 & C, T, SD, s90q3 & -2.72 & -3.80 (a) & C, T, $f_{t}^{(3)}$ & -0.69 & -2.80 \\
$\Delta(g d p-e)$ & 4 & C, SD, i90q3 & $-6.41^{* *}$ & -2.89 & C, SD, i90q3 & $-3.51^{*}$ & -2.94 \\
\hline$e$ & 4 & C, T, SD, s90q3 & -2.29 & $-3.80(\mathrm{a})$ & $\mathrm{C}, \mathrm{T}, f_{t}^{(3)}$ & -1.63 & -2.80 \\
$\Delta e$ & 3 & C, SD, i90q3 & $-8.79^{* *}$ & -2.89 & $\mathrm{C}, \mathrm{SD}, \mathrm{i} 90 \mathrm{q} 3$ & $-6.68^{* *}$ & -2.94 \\
\hline$u$ & 5 & C, T, SD, DT, s90q3 & -3.02 & $-4.04(\mathrm{c})$ & $\mathrm{C}, \mathrm{T}, f_{t}^{(2)}$ & -2.73 & -2.80 \\
$\Delta u$ & 4 & C, T, SD, s90q3 & $-4.44^{* *}$ & $-3.80(\mathrm{a})$ & $\mathrm{C}, \mathrm{SD}, \mathrm{i} 90 \mathrm{q} 3$ & $-4.40^{* *}$ & -2.94 \\
\hline$(w-p)$ & 5 & C, T, SD, s90q3 & -2.31 & $-3.80(\mathrm{a})$ & $\mathrm{C}, \mathrm{T}, f_{t}^{(2)}$ & -0.14 & -2.80 \\
$\Delta(w-p)$ & 4 & C, SD, i90q3 & $-3.56^{* *}$ & -2.89 & $\mathrm{C}, \mathrm{SD}, \mathrm{i} 90 \mathrm{q} 3$ & $-4.11^{* *}$ & -2.94 \\
\hline \hline
\end{tabular}

Note: (a) and (c) denote model A and C from Perron (1989). Column 2 indicates the number of lagged differences determined according to the highest significant lag. $*$ and $* *$ denote significance at 5\% and 1\% respectively. ADF critical values are from MacKinnon (1991). The $\tau$ test statistic is $\tau_{\text {int }}^{+}$for the levels and $\tau_{\text {int }}^{+0}$ for the first differences as proposed by Lanne et al. (1999). Critical values are from Table 1 in Lanne et al. (1999). $f_{t}^{(i)}$ are shift functions defined in Table 3 of Lanne et al. (1999)

version $\tau_{\text {int }}^{+}$that allows for a linear trend and a shift function when applied to the original series. $^{3}$ We choose the shift function by visual inspection of the adjusted series, such that the level shift is captured in the best possible way. For the first differences we compute $\tau_{\text {int }}^{+0}$, which includes a constant and an impulse dummy only. Table 1 lists results of unit root tests applied to the levels as well as to the first differences of the series. ${ }^{4}$ Results of both test types suggest that $g d p_{t}-e_{t}, e_{t}, u_{t}$, and $w_{t}-p_{t}$ are integrated of order one, i.e. I(1).

To test for the number of cointegration relations, we set up an initial VAR and include a constant and seasonal dummies as deterministic terms. ${ }^{5}$ To account for the level shift, we also include a step dummy $s 90 q 3_{t}$, which is one from the third quarter of 1990 and zero elsewhere and an impulse dummy $i 90 q 3_{t}$ that is one in the third quarter of 1990 and zero elsewhere. We use the AIC, SC and HQ information criteria (see Lütkepohl (1991), Ch. 4) to determine the lag length of the VAR process. All three criteria suggest a lag length of $p=5$ when the maximum lag length is $p_{\max }=8$. This lag length is also confirmed by a sequence of F-tests. The reduction of a $\operatorname{VAR}(6)$ to a $\operatorname{VAR}(5)$ cannot be rejected $(F(16,254)=1.64[0.059])$ on the $5 \%$ level while further reduction to a $\operatorname{VAR}(4)$ is clearly rejected $(F(16,266)=4.76[0.000])$. In addition a number of misspecification tests have been performed. A single equation LM-test indicates that there is some autocorrelation left in the unemployment equation. Moreover, a vector LM-test on the system indicates autocorrelated errors. Increasing the lag length of the VAR model does not fix the autocorrelation problem possibly indicating that a VARMA

\footnotetext{
${ }^{3}$ The $\tau_{\text {int }}^{+}$-test performed relatively well in comparison to other test variants (see Lanne et al. (1999)).

${ }^{4}$ The unit root tests have been computed by Eviews 3.1 and GAUSS.

${ }^{5}$ PcFiml by Doornik \& Hendry (1997) has been used for the cointegration analysis.
} 
Table 2. Cointegration Tests

\begin{tabular}{cccccccc}
\hline \hline & & \multicolumn{3}{c}{ Johansen Trace Test } & \multicolumn{3}{c}{ S\&L Test } \\
$H_{0}:$ & $H_{1}:$ & $L R_{J \& N}$ & $95 \%$ & DisCo $95 \%$ & $L R_{S \& L}$ & $90 \%$ & $95 \%$ \\
\hline$r=0$ & $r>0$ & $60.2^{* *}$ & 47.2 & 55.9 & $42.5^{*}$ & 42.0 & 45.1 \\
$r=1$ & $r>1$ & 24.1 & 29.7 & 35.7 & 23.9 & 25.9 & 28.5 \\
$r=2$ & $r>2$ & 10.9 & 15.4 & 19.7 & 10.8 & 13.9 & 15.9 \\
\hline \hline
\end{tabular}

Note: $*(* *)$ denotes significance at the $5 \%$ (10\%) level. Critical values in column 4 from Table 1 in Osterwald-Lenum (1992), values in column 5 have been simulated using DisCo by Johansen \& Nielsen (1993). S\&L test critical values are taken from Table 1 in Lütkepohl \& Saikkonen (2000).

representation would be more appropriate. While uncorrelated errors would be desirable, they are not a precondition for the validity of the cointegration tests. Therefore, we continue the analysis using the $\operatorname{VAR}(5)$ model.

To test for cointegration means estimating the rank $r$ of $\Pi$ from the vector error correction representation (2.4). We use two cointegration tests that explicitly take the level shifts into account and present the results in Table 2. The first test has been proposed by Johansen \& Nielsen (1993). In their test, the distribution of the statistic $L R_{J \& N}$ depends on the relative timing of the break. Therefore, we have simulated asymptotic critical values for the present case when a step dummy enters the system in restricted form using the program DisCo developed by Johansen \& Nielsen (1993). According to the simulated critical values in Table 2 we reject the hypothesis of no cointegration on the $5 \%$ level. Moreover, the hypothesis that the cointegration rank is one cannot be rejected on conventional significance levels. Another test for processes with structural shifts has been proposed by Lütkepohl \& Saikkonen (2000). The idea of this test is to estimate the deterministic part including the shift dummy by a GLS procedure, subtract it from the original series and apply a trace test to the adjusted series. In line with results of the Johansen \& Nielsen test, the test statistic $L R_{S \& L}$ suggests one cointegration relation.

Since the theoretical model implies up to two cointegration relations, the results in Table 2 may be just the consequence of a lack of power problem of the cointegration tests. We therefore check, whether estimating under $r=r k(\Pi)=2$ is a plausible alternative. Results for a model with two cointegration vectors are given in Appendix B. It turns out, however, that the resulting labor demand function has implausible signs on the coefficients of output $\left(g d p_{t}\right)$ and real wages $\left(w_{t}-p_{t}\right)$. As a consequence, our preferred specification is a model with one cointegration relation and we continue to identify this cointegrating vector.

The theoretical model suggests that this cointegration relation is either a labor demand or a wage setting relation. We use the tools of restricted cointegration analysis to identify the cointegration vector. In the first row of Table 3 we report the estimated cointegration 
Table 3. Restricted Cointegration Analysis

\begin{tabular}{ccccccc}
\hline \hline & $g d p-e$ & $e$ & $u$ & $(w-p)$ & $s 90 q 3$ & LR-test \\
\hline & -0.973 & -0.146 & 2.387 & 1 & 0.073 & - \\
& $(0.101)$ & $(0.314)$ & $(0.523)$ & - & $(0.078)$ & \\
\hline \multirow{2}{*}{ H1: } & -0.955 & 0 & 2.485 & 1 & 0.039 & $\chi^{2}(1)=0.17[0.68]$ \\
& $(0.085)$ & - & $(0.485)$ & - & $(0.015)$ & \\
\hline & & & & & & \\
H2: & -1 & 0 & 2.733 & 1 & 0.039 & $\chi^{2}(2)=0.42[0.81]$ \\
& - & - & $(0.237)$ & - & $(0.015)$ & \\
\hline \hline
\end{tabular}

Note: Standard error in parentheses

vector $\beta$, where we have normalized the real wage coefficient to unity. Associated standard errors are given in parentheses. The vector is likely to represent a wage setting relation given the coefficient estimate on $e$ with a standard error more than twice as large as the estimate itself. In a next step, we test the exclusion of $e$ from $\beta$, which cannot be rejected by a corresponding Likelihood Ratio $(\mathrm{LR})$ test $\left(\chi^{2}(1)=0.17[0.68]\right)$. Finally, we impose a $[1,-1]$ relation between real wages and productivity, which is not rejected either. The restricted cointegration vector $\beta$ is identified as a wage setting relation according to the theoretical model:

$$
w_{t}-p_{t}=(g d p-e)_{t}-2.733 u_{t}-0.039 s 90 q 3_{t}
$$

The estimated wage setting relation reflects that the German labor market is not competitive and outsiders influence the wage setting as the coefficient on unemployment suggests. $\widehat{\gamma}=2.733$ is often interpreted as the long run elasticity of real wages with respect to unemployment. This interpretation can be problematic, nevertheless the estimated coefficient can be compared to results from other studies. Carstensen \& Hansen (2000) find for the West German labor market a value of 1.824. In earlier studies Hansen (2000) finds a number of 1.95 for the preunification period in Germany, while Bean, Layard \& Nickell (1986) find an estimate of 3.31. The values are not directly comparable, because estimates are derived from different estimation methods, variables and data sets. However, the comparison gives a rough indication that the estimate $\widehat{\gamma}$ is plausible. The identified cointegration vector is used to set up the VECMs used in the structural analysis. 


\section{Structural Analysis}

\subsection{Identification of the Labor Market VECM}

In this section we derive identifying restrictions from the theoretical model and from the results of the cointegration analysis and use estimates of the identified model to compute IRF and FEVD. We use both a standard SVECM and a Subset SVECM and compare the results.

We know from Section 2 that we need $K(K-1) / 2=4(4-1) / 2=6$ additional linearly independent restrictions coming from economic theory to exactly identify the structural shocks. In addition, we know from the common trends literature that in a 4-dimensional system with one cointegration relation, only 3 shocks can have permanent effects. Moreover, the cointegration analysis from the previous section indicates that wage setting is a stationary relation. Our theoretical model then implies that the wage setting shock $\varepsilon_{w, t}$ does not have permanent effects on the system variables, which can be expressed by a zero column in $C(1){\overline{A_{0}}}^{-1}$ as

$$
C(1) \bar{A}_{0}^{-1}=\left[\begin{array}{llll}
* & * & * & 0 \\
* & * & * & 0 \\
* & * & * & 0 \\
* & * & * & 0
\end{array}\right] .
$$

If we assume constant returns to scale $(\rho=1)$, it is easy to see from the solution of theoretical model (3.5) that shocks to labor demand $\left(\varepsilon_{d}\right)$, to labor supply $\left(\varepsilon_{s}\right)$ and to wage setting $\left(\varepsilon_{w}\right)$ have no permanent effects on productivity, which can be written as

$$
C(1) \bar{A}_{0}^{-1}=\left[\begin{array}{cccc}
* & 0 & 0 & 0 \\
* & * & * & * \\
* & * & * & * \\
* & * & * & *
\end{array}\right] .
$$

(R1) essentially sets up four linear equations including all elements of $C(1)$. Because $C(1)$ has reduced rank $(r k=3)$, only three equations are linearly independent. Obviously, (R2) imposes only two independent restrictions, because $\left(C(1) \bar{A}_{0}^{-1}\right)_{14}=0$ is imposed by (R1) already. Consequently, (R1) and (R2) provide only 5 linearly independent restrictions. Therefore, we need one additional restriction. The theoretical model does not provide more sensible long run restrictions than already imposed by (R1) and (R2). Consequently, we impose one contemporaneous restriction. Of course, contemporaneous restrictions are always somewhat arbitrary. Nevertheless, we assume that the labor demand shock $\varepsilon_{d}$ does not affect real wages in the initial quarter, which means

$$
\left(\bar{A}_{0}^{-1}\right)_{42}=0 \text {. }
$$


(R3) can be justified by the fact that wage contracts normally fix wages for more than one quarter. The restriction set (R1)-(R3) exactly identifies the model, which can now be estimated by the method described in Section 2.

First, we estimate the standard VECM with identifying restrictions explained above. The short run parameters $\left(\alpha, \Gamma_{1}, \ldots, \Gamma_{p-1}\right)$ in this first model are unrestricted in the sense that we do not impose zero restrictions. Using the estimates $\hat{\alpha}, \hat{\Gamma}_{1}, \ldots, \hat{\Gamma}_{p-1}$ given in Table 7 (Appendix C) and $\hat{\Sigma}_{u}$, we compute the contemporaneous impact matrix as

$$
\bar{A}_{0}{ }^{-1}=\left[\begin{array}{rrrr}
1.036 & -0.194 & -0.149 & -0.158 \\
(0.644) & (0.151) & (0.162) & (0.188) \\
-0.322 & 1.206 & 0.433 & 0.525 \\
(0.343) & (0.298) & (0.542) & (0.227) \\
-0.042 & -0.097 & 0.166 & -0.109 \\
(0.049) & (0.088) & (0.099) & (0.037) \\
0.471 & 0 & -0.793 & -1.378 \\
(0.437) & & (0.572) & (0.199)
\end{array}\right] \times 10^{-2}
$$

and the identified long-run impact matrix as

$$
C(1) \bar{A}_{0}^{-1}=\left[\begin{array}{rrrr}
1.157 & 0 & 0 & 0 \\
(0.853) & & & \\
-0.376 & 1.118 & -0.024 & 0 \\
(0.429) & (0.306) & (0.479) & \\
-0.180 & -0.163 & 0.258 & 0 \\
(0.175) & (0.119) & (0.172) & \\
1.651 & 0.450 & -0.710 & 0 \\
(1.293) & (0.328) & (0.474) &
\end{array}\right] \times 10^{-2} .
$$

In parentheses we provide standard deviations for each point estimator from 1000 bootstrap replications of the model. Only a few coefficients of these matrices are significantly different from zero, indicating substantial estimation uncertainty. The third row of the impact matrix (5.1) shows the long run response of unemployment after a technology, a labor demand, a labor supply and a wage shock. As imposed by (R1) the long run effect of a wage setting shock is zero. The long run responses of unemployment to the other three shocks show the expected sign, however, they are not significant according to a \pm 2 standard error criterion.

To reduce estimation uncertainty we wish to impose a set of zero restrictions on $\alpha$, $\Gamma_{1}, \ldots, \Gamma_{p-1}$ prior to computing $\bar{A}_{0}^{-1}$, i.e. we want to estimate a Subset SVECM. A number of statistical subset methods have been proposed in the literature (see Lütkepohl (1991), Ch. 5 and Brüggemann \& Lütkepohl (2000)). A more general approach is taken by Krolzig \& Hendry (2000) who implement the general-to-specific approach in a computer algorithm. Krolzig (2000) has applied the algorithm to VAR models and compared results from PcGets with results from Brüggemann \& Lütkepohl (2000). Although a more detailed comparison may be required, results indicate that PcGets in its present form has no major advantage over strategies suggested in Brüggemann \& Lütkepohl (2000). Therefore, we simply use a 
single equation strategy based on $t$-values where the critical values depend on the sample size and the reduction step to find zero entries. Monte Carlo simulation results suggest that a single equation strategy performs as well as a system strategy, even in the presence of cross equation correlation. We use the Sequential Elimination of Regressors (SER/TP) proposed in Brüggemann \& Lütkepohl (2000) in conjunction with the Schwarz (SC) criterion, because results from this simple strategy most closely resemble results from PcGets. ${ }^{6}$

We start from the full VECM and search for zero entries in $\Gamma_{1}, \ldots, \Gamma_{p-1}$ first. After this search we delete loading coefficients $\alpha_{i}$ if they are not significant on the $5 \%$ level. This sequence emphasizes the importance of the loading coefficients. Applying the SER/TP strategy to the labor market model results in a substantially reduced number of parameters. The Subset VECM has 42 zero restrictions on the 88 model parameters. This includes one zero restriction on the loading coefficient of the productivity equation. The Subset VECM is estimated by EGLS and results are listed in Table 8 (Appendix C). On the basis of the Subset VECM estimates we compute again the contemporaneous impact matrix

$$
\bar{A}_{0}{ }^{-1}=\left[\begin{array}{rrrr}
0.910 & -0.227 & -0.351 & 0.000 \\
(0.067) & (0.086) & (0.087) & (0.000) \\
-0.142 & 1.156 & 0.671 & 0.242 \\
(0.168) & (0.139) & (0.338) & (0.114) \\
-0.009 & -0.128 & 0.135 & -0.109 \\
(0.024) & (0.054) & (0.036) & (0.021) \\
0.452 & 0 & -0.874 & -1.284 \\
(0.179) & & (0.218) & (0.116)
\end{array}\right] \times 10^{-2}
$$

and the corresponding long run impact matrix

$$
C(1) \bar{A}_{0}^{-1}=\left[\begin{array}{rrrr}
1.076 & 0 & 0 & 0 \\
(0.140) & & & \\
-0.267 & 0.993 & 0.332 & 0 \\
(0.269) & (0.138) & (0.267) & \\
-0.163 & -0.199 & 0.201 & 0 \\
(0.079) & (0.076) & (0.059) & \\
1.525 & 0.549 & -0.554 & 0 \\
(0.291) & (0.210) & (0.162) &
\end{array}\right] \times 10^{-2} .
$$

There is a change in sign for the long run effect of the labor supply shock on employment $\left(C(1) \bar{A}_{0}^{-1}\right)_{23}$. The positive coefficient estimate from the subset model is economically plausibel, however still not significant. Moreover, it is particularly interesting to compare the third row of (5.2) to the third row of (5.1). While estimates from the subset model show the same sign and similar magnitudes as in the full model, the estimated standard errors now indicate a significant long run impact of $\varepsilon_{g d p}, \varepsilon_{d}$ and $\varepsilon_{s}$. One possible conclusion is that the Subset VECM reduces uncertainty substantially. However, we do not account for uncertainty of the model selection process and hence, the subset results may be too optimistic.

\footnotetext{
${ }^{6} \mathrm{~A}$ model specified by PcGets $1.00 \mathrm{~g}$ (beta) has a very similar structure and is available on request.
} 

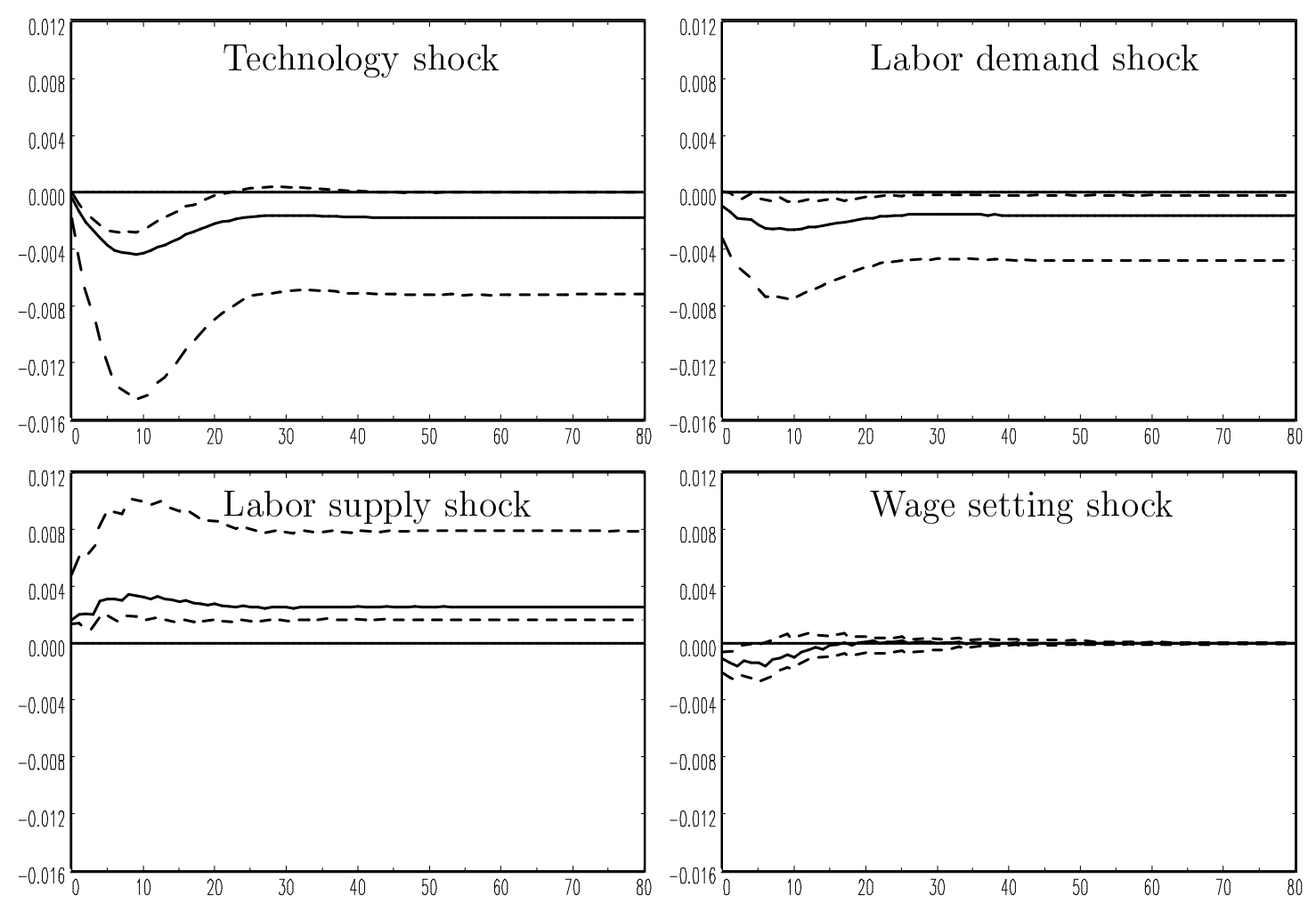

Figure 2. Responses of Unemployment in full SVECM model

\subsection{Impulse Responses Analysis}

To get a more complete picture of the dynamic interaction between variables, we compute impulse responses from the standard SVECM as well as from the Subset SVECM. We provide bootstrap confidence bands computed by the percentile method proposed by Hall (1992) and recommended by Benkwitz, Lütkepohl \& Neumann (2000). To compute the confidence bands we fix the estimated cointegration relation in the bootstrap. ${ }^{7}$ Figure 2 shows the responses of unemployment to a technology, a labor demand, a labor supply and a wage setting shock from the full SVECM with $95 \%$ confidence intervals. A technology shock drives unemployment down. From the upper left panel we see that this negative effect is significant even in the long run. Adjustment to new equilibrium takes about eight years. A labor demand shock leads to a significant drop in unemployment and adjustment takes roughly six years. According to the bootstrap confidence bands, the effect is significant even in the long run. The labor supply shock has a significant positive impact on unemployment and adjustment takes about 7 years. The wage shock has a zero long run effect as imposed by (R1). In the short run, the negative response of unemployment seems to be implausible. However, compared to the other shocks in the system, the response is very small.

\footnotetext{
${ }^{7}$ Benkwitz, Lütkepohl \& Wolters (2001) find only minor differences between intervals computed with a fixed and a reestimated $\beta$.
} 

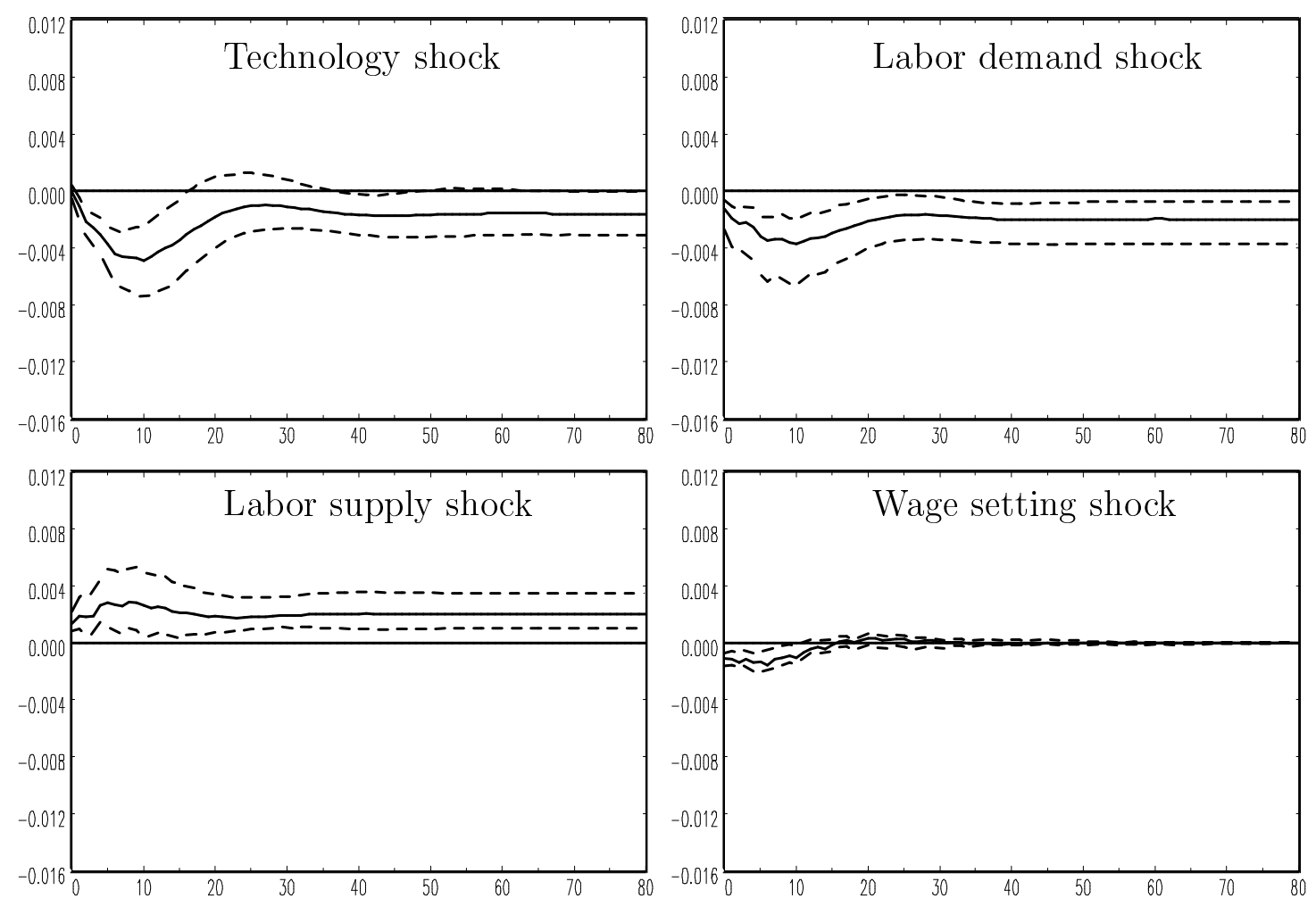

Figure 3. Responses of Unemployment in Subset SVECM model

With exception of the response to the wage setting shock, the confidence bands are very asymmetric, which indicates an asymmetric bootstrap distribution. In such cases interpreting impulse responses with asymptotic confidence bands would be risky, because plus/minus 2 standard error bands are necessarily symmetric and may draw a very misleading picture of the true dynamic interaction in the model. We therefore recommend using a bootstrap method to compute confidence bands in small sample situations. The asymmetry of the confidence bands also explains why some long run effects appear significant from the bootstrap exercise but not significant based on the standard errors in (5.1).

Figure 3 plots the responses of unemployment from the Subset SVECM model. A comparison to Figure 2 reveals that the point estimates are basically unchanged, although we have restricted 42 coefficients to zero. Thus, the Subset VECM captures the same dynamics as the full model indicating that the restrictions are sensible. Moreover, the confidence intervals are no longer asymmetric and results from the impulse response analysis are in line with standard errors of the impact matrices. This observation may be due to the fact, that the ratio of observations to parameters comes closer to the asymptotic situation in the Subset VECM than in a full VECM. Similar to the results from the full SVECM we find negative significant long run responses of unemployment to shocks in technology and labor demand and a positive response to labor supply shocks.

Results from both models indicate that technology and labor supply shocks are important 
Table 4. Forecast Error Variance Decomposition

\begin{tabular}{rcccc|cccc}
\hline \hline & \multicolumn{4}{c}{ Full VECM } \\
$h$ & $\varepsilon_{g d p}$ & $\varepsilon_{d}$ & $\varepsilon_{s}$ & $\varepsilon_{w}$ & $\varepsilon_{g d p}$ & $\varepsilon_{d}$ & $\varepsilon_{s}$ & $\varepsilon_{w}$ \\
\hline 1 & 0.035 & 0.185 & 0.546 & 0.235 & 0.002 & 0.350 & 0.390 & 0.258 \\
2 & 0.134 & 0.193 & 0.468 & 0.205 & 0.087 & 0.378 & 0.364 & 0.171 \\
3 & 0.220 & 0.211 & 0.381 & 0.188 & 0.198 & 0.365 & 0.290 & 0.147 \\
4 & 0.297 & 0.213 & 0.336 & 0.153 & 0.275 & 0.339 & 0.263 & 0.123 \\
5 & 0.338 & 0.193 & 0.343 & 0.126 & 0.311 & 0.311 & 0.271 & 0.107 \\
6 & 0.373 & 0.188 & 0.333 & 0.106 & 0.344 & 0.306 & 0.261 & 0.089 \\
7 & 0.400 & 0.187 & 0.316 & 0.097 & 0.381 & 0.303 & 0.236 & 0.080 \\
8 & 0.423 & 0.188 & 0.304 & 0.085 & 0.411 & 0.298 & 0.221 & 0.070 \\
9 & 0.435 & 0.185 & 0.306 & 0.075 & 0.429 & 0.294 & 0.216 & 0.062 \\
10 & 0.445 & 0.186 & 0.304 & 0.066 & 0.441 & 0.294 & 0.211 & 0.054 \\
20 & 0.443 & 0.195 & 0.326 & 0.036 & 0.459 & 0.315 & 0.196 & 0.031 \\
30 & 0.406 & 0.199 & 0.365 & 0.029 & 0.424 & 0.326 & 0.222 & 0.027 \\
40 & 0.381 & 0.202 & 0.393 & 0.024 & 0.397 & 0.332 & 0.248 & 0.024 \\
50 & 0.363 & 0.203 & 0.413 & 0.021 & 0.379 & 0.336 & 0.264 & 0.021 \\
60 & 0.350 & 0.204 & 0.427 & 0.018 & 0.365 & 0.341 & 0.276 & 0.018 \\
70 & 0.340 & 0.205 & 0.439 & 0.016 & 0.353 & 0.344 & 0.287 & 0.017 \\
80 & 0.332 & 0.206 & 0.448 & 0.015 & 0.343 & 0.346 & 0.295 & 0.015 \\
\hline \hline
\end{tabular}

for the determination of unemployment. In addition we find that labor demand shocks are also important. This contrasts the result from Carstensen \& Hansen (2000) for West Germany. They find that labor demand shocks are neither in the short run nor in the long run an important source of unemployment. The impulse response analysis indicates that adjustment is rather sluggish and takes up to 8 years. Though computed from a different model, Carstensen \& Hansen (2000) obtain a substantially faster adjustment which takes up to 4 years. A comparison to results from Jacobson et al. (1997) who find 1-2 years for Norway and Schweden, and 4 years for Denmark, shows that adjustment in Germany is considerably slower than in Scandinavian countries.

\subsection{Forecast Error Variance Decomposition}

To assess the importance of different shocks we compute the forecast error variance decomposition for unemployment from the full and the Subset SVECM. Table 4 shows the decomposition for unemployment, i.e. the proportion of forecast error variance in unemployment, $h$ periods ahead accounted for by the structural shocks $\varepsilon_{g d p}, \varepsilon_{d}, \varepsilon_{s}$ and $\varepsilon_{w}$. One finding is that labor demand, labor supply and wage setting shocks are important for the short run determination of unemployment. With increasing horizon $h$ the technology shock becomes 
more, while shocks to wage setting become less important. In the long run (after 80 quarters) technology, labor demand, and labor supply shocks are equally important as indicated by the last row of Table 4. Again, this contrasts results from Carstensen \& Hansen (2000) for West Germany. In their study labor demand is a stationary relationship and hence, they impose a zero long run effect of labor demand shocks.

The differences in FEVD between full and Subset VECM are small in general but our results suggest that the labor demand shock is slightly more important in the Subset SVECM than in the full SVECM. However, this interpretation neglects the underlying estimation uncertainty and seems risky.

\section{Conclusion}

In this paper we propose an estimation method for SVECMs when the short run parameters are restricted. If the model is exactly identified, the suggested method is fast and allows the computation of bootstrap confidence intervals for impulse responses, which may be more appropriate in small samples than the usually symmetric asymptotic standard error bands. One important drawback of the proposed estimation procedure for Subset SVECMs is the limitation to just identified models. Since the nonlinear equation system has no unique solution in the presence of overidentifying structural restrictions, the method cannot be used in such cases.

We illustrate the use of the Subset SVECM method with German labor market data. A cointegration analysis shows that hourly real wages, productivity and unemployment are cointegrated and form a sensible wage setting relation. In a second step, we make use of a statistical procedure to find an appropriate Subset VECM and identify the structural shocks using a simple macroeconomic model of the labor market. We use the estimated impact matrices from the full and the Subset SVECM to compute identified impulse responses and forecast error variance decompositions. From the structural analysis we find that technology, labor demand and labor supply shocks are equally important for unemployment in the long run, which contrasts with results for West Germany in Carstensen \& Hansen (2000). Moreover, adjustment to a new labor market equilibrium is rather sluggish and takes up to eight years.

The comparison between full SVECM and Subset SVECM illustrates, that estimates of impact matrices and IRF from the Subset SVECM tend to be more precise. In addition, bootstrap confidence bands from the Subset SVECM are no longer asymmetric. This shows that additional zero restrictions on the short run parameters reduce estimation uncertainty. Moreover, the differences in FEVD between full and Subset VECM are small. Overall, the results indicate that Subset SVECMs can be a useful modeling tool. In future studies, it may therefore be worthwhile to develop estimation methods of Subset SVECM for overidentified models. 


\section{References}

Amisano, G. \& Giannini, C. (1992). Topics in Structural VAR Econometrics, 2nd edn, Springer-Verlag.

Bean, C., Layard, P. R. G. \& Nickell, S. J. (1986). The rise in unemployment: A multicountry study, Economica 53: 1-22.

Benkwitz, A., Lütkepohl, H. \& Neumann, M. H. (2000). Problems related to bootstrapping impulse responses of autoregressive processes, Econometric Reviews 19: 69-103.

Benkwitz, A., Lütkepohl, H. \& Wolters, J. (2001). Comparison of bootstrap confidence intervals for impulse responses of german monetary systems, Macroeconomic Dynamics forthcoming.

Breitung, J. (2000). Structural Inference in Cointegrated Vector Autoregressive Models, Habilitationsschrift, Humboldt-Universität zu Berlin.

Brüggemann, R. \& Lütkepohl, H. (2000). Lag selection in Subset VAR models with an application to a U.S. monetary system, Discussion Paper 37, Sonderforschungsbereich 373, Humboldt-Universität zu Berlin.

Carstensen, K. \& Hansen, G. (2000). Cointegration and common trends on the West German labour market, Empirical Economics 25: 475-493.

Christiano, L., Eichenbaum, M. \& Evans, C. (1999). Monetary shocks: What have we learned and to what end?, in J. Taylor \& M. Woodford (eds), The Handbook of Macroeconomics, Amsterdam: Elsevier Science Publication.

Dolado, J. J. \& Jimeno, J. F. (1997). The causes of Spanish unemployment: A structural VAR approach, European Economic Review 41: 1281-1307.

Doornik, J. A. \& Hendry, D. F. (1997). Modelling Dynamic Systems Using PcFiml 9.0 for Windows, Thomson Publishing, Institute of Economics and Statistics, University of Oxford.

Galí, J. (1999). Technology, employment, and the business cycle: Do technology shocks explain aggregate fluctuations?, American Economic Review 89(1): 249-271.

Hall, P. (1992). The Bootstrap and Edgeworth Expansion, New York: Springer.

Hansen, G. (2000). The German labour market and the unification shock, Economic Modelling 17(3): 439-454.

Jacobson, T., Vredin, A. \& Warne, A. (1997). Common trends and hysteresis in Scandinavian unemployment, European Economic Review 41: 1781-1816. 
Johansen, S. (1995). Likelihood-Based Inference in Cointegrated Vector Autogressive Models, Oxford University Press.

Johansen, S. \& Nielsen, B. (1993). Manual for the simulation program DisCo, Institute of Mathematical Statistics, University of Copenhagen.

King, R. G., Plosser, C. I., Stock, J. H. \& Watson, M. (1991). Stochastic trends and economic fluctuations, American Economic Review 81(4): 819-840.

Krolzig, H.-M. (2000). Genral-to-specific reductions of vector autoregressive processes, Working Paper W34, www.nuff.ox.ac.uk/Economics/papers/2000/w34/frohn.pdf.

Krolzig, H.-M. \& Hendry, D. F. (2000). Computer automation of general-to-specific model selection procedures, Journal of Economic Dynamics and Control forthcoming.

Lanne, M., Lütkepohl, H. \& Saikkonen, P. (1999). Comparison of unit root tests for time series with level shifts, Discussion Paper 88, Sonderforschungsbereich 373, HumboldtUniversität zu Berlin.

Lütkepohl, H. (1991). Introduction to Multiple Time Series Analysis, Berlin: Springer-Verlag.

Lütkepohl, H. (2001). Vector autoregressions, in B. Baltagi (ed.), Companion to Theoretical Econometrics, Blackwell, Oxford, pp. 678-699.

Lütkepohl, H. \& Saikkonen, P. (2000). Testing for the cointegrating rank of a VAR process with a time trend, Journal of Econometrics 95: 177-198.

MacKinnon, J. (1991). Critical values for co-integration tests, in R. Engle \& C. Granger (eds), Long-Run Economic Relationships, Oxford University Press, pp. 276-276.

Mosconi, R. (1998). Malcom: The Theory and Practice of Cointegration Analysis in RATS, Milano: Cafoscarina.

Osterwald-Lenum, M. (1992). A note with quantiles of the asymptotic distribution of the maximum likelihood cointegration rank test statistics, Oxford Bulletin of Economics and Statistics 54: 461-472.

Perron, P. (1989). The great crash, the oil price shock, and unit root hypothesis, Econometrica 57(6): 1361-1401.

Rotemberg, J. \& Woodford, M. (1992). Oligopolistic pricing and the effects of aggregate demand on economic activity, Journal of Political Economy 100(6): 1153-1207.

Sims, C. A. (1980). Macroeconomics and reality, Econometrica 48: 1-48. 


\section{A Data Sources}

All series in this paper are quarterly data and have been constructed from the Deutsches Institut für Wirtschaftsforschung (DIW) database. The data refer to West Germany until 1990:2 and the unified Germany afterwards. West German (unified German) series have a WH $(\mathrm{GH})$ prefix in the DIW database codes, which are omitted from the following list.

1. $g d p$ : Real gross domestic product GDP, DIW code: 12011. $g d p$ is $\log (\mathrm{GDP})$.

2. $p$ : GDP price deflator $(1991=100)$, DIW code: $12011 \mathrm{X} . p$ is $\log (\mathrm{GDP}$ price deflator $)$.

3. e: Employment in hours in, DIW code: 1101. $e$ is $\log ($ Employment in hours).

4. $u$ : The unemployment series is constructed dividing the number of unemployed by the sum of people in employment and unemployment. DIW code: $u=1110 /(1110+$ 1102).

5. w: We use the net nominal wage bill (DIW code: 2005) and divide by the hours in employment (DIW code 1101) to compute the nominal hourly wages. $w$ is $\log (2005 / 1101)$.

From these series we construct

$$
y_{t}=\left[(g d p-e)_{t}, e_{t}, u_{t},(w-p)_{t}\right]^{\prime}
$$

that is used in the analysis. The data set $y_{t}$ can be downloaded from the internet at http://ise.wiwi.hu-berlin.de/ brueggem/research/data/

\section{B Two Cointegrating Vectors}

In this section we allow for the possibility of two cointegrating vectors, to check whether this is a plausible alternative to the model used in the text. For this purpose we assume that $r=2$ and present results from the restricted cointegration analysis in Table 5. First, we impose just identifying restrictions by excluding $e_{t}$ from the first and $u_{t}$ from the second cointegration vector and normalizing on $\left(w_{t}-p_{t}\right)$. The coefficients of the wage setting relation closely resemble those from the text when we restrict the coefficient on productivity to be -1 . If we rewrite the second cointegration vector $\beta_{2}$ in form of the labor demand function (3.2) we get

$$
e_{t}=-1.118 g d p_{t}+1.199\left(w_{t}-p_{t}\right)+.555 s 90 q 3_{t}
$$

which has implausible signs on $g d p_{t}$ and $\left(w_{t}-p_{t}\right)$. We therefore regard a model with one cointegrating vector as the preferred specification. Nevertheless, we compute identified impulse responses and the FEVD of unemployment under the assumption $r=2$. Of course, 
Table 5. Restricted Cointegration Analysis, $r=2$

\begin{tabular}{lccccccc}
\hline \hline & & $g d p-e$ & $e$ & $u$ & $(w-p)$ & $s 90 q 3$ & LR-test \\
\hline$\beta_{1}^{\prime}$ & -0.978 & 0 & 2.608 & 1 & 0.038 & - \\
& $(0.082)$ & - & $(0.431)$ & - & $(0.015)$ & \\
& & & & & & & \\
& $\beta_{2}^{\prime}$ & -0.921 & -1.726 & 0 & 1 & 0.453 & \\
& $(0.184)$ & $(0.575)$ & - & - & $(0.141)$ & \\
\hline H1: & & & & & & & \\
& $\beta_{1}^{\prime}$ & -1 & 0 & 2.730 & 1 & 0.038 & \\
& & - & - & $(0.237)$ & - & $(0.015)$ & \\
& & & & & & & \\
& $\beta_{2}^{\prime}$ & -0.932 & -1.766 & 0 & 1 & 0.463 & \\
& $(0.183)$ & $(0.585)$ & - & - & 0.143 & \\
& & & & & & $\chi^{2}(1)=0.04[0.84]$ \\
\hline \hline
\end{tabular}

Note: Standard error in parentheses

we have to adjust our identification scheme from the text accordingly. With $r=2$ only $k=K-r$ shocks have permanent effects. Moreover, to identify the two permanent shocks we need $k(k-1) / 2=1$ additional restriction and again assume constant returns to scale. These two restriction sets can be written as:

$$
C(1) \bar{A}_{0}{ }^{-1}=\left[\begin{array}{cccc}
* & 0 & 0 & 0 \\
* & 0 & * & 0 \\
* & 0 & * & 0 \\
* & 0 & * & 0
\end{array}\right]
$$

To identify the two transitory shocks we imposes $r(r-1) / 2=1$ restriction on the contemporaneous impact matrix. In particular, we choose the same restriction as in the Section 5 :

$$
\left(\bar{A}_{0}^{-1}\right)_{42}=0 \text {. }
$$

Note, that this restriction was needed in Section 5 to identify the permanent shocks. Here, however, it identifies the transitory shocks. The impulse responses are depicted in Figure 4 and 5. Compared to the preferred model, the responses of unemployment to a productivity, a labor supply, and a wage shock are virtually unchanged. As imposed the labor demand shock has now a zero long run impact on unemployment. Unemployment responds positively to a positive shock in labor demand in the short run, which is somewhat puzzling and might be due to the implausible signs of the identified labor demand relation. The result from the FEVD in Table 6 basically reflects the imposed restrictions: Labor demand and wage setting shocks are not an important source of unemployment in the long run. 

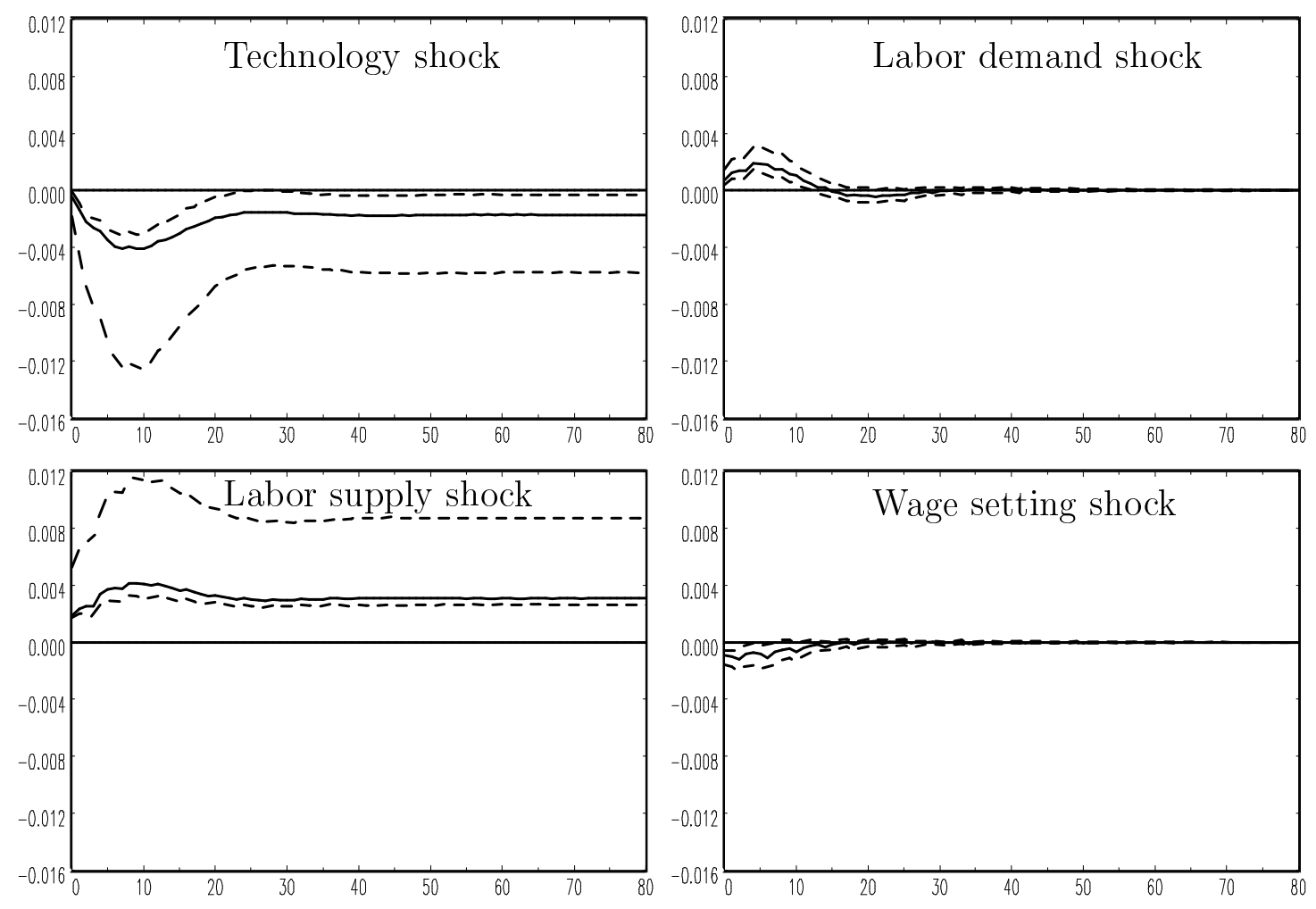

Figure 4. Responses of Unemployment in full SVECM, $r=2$
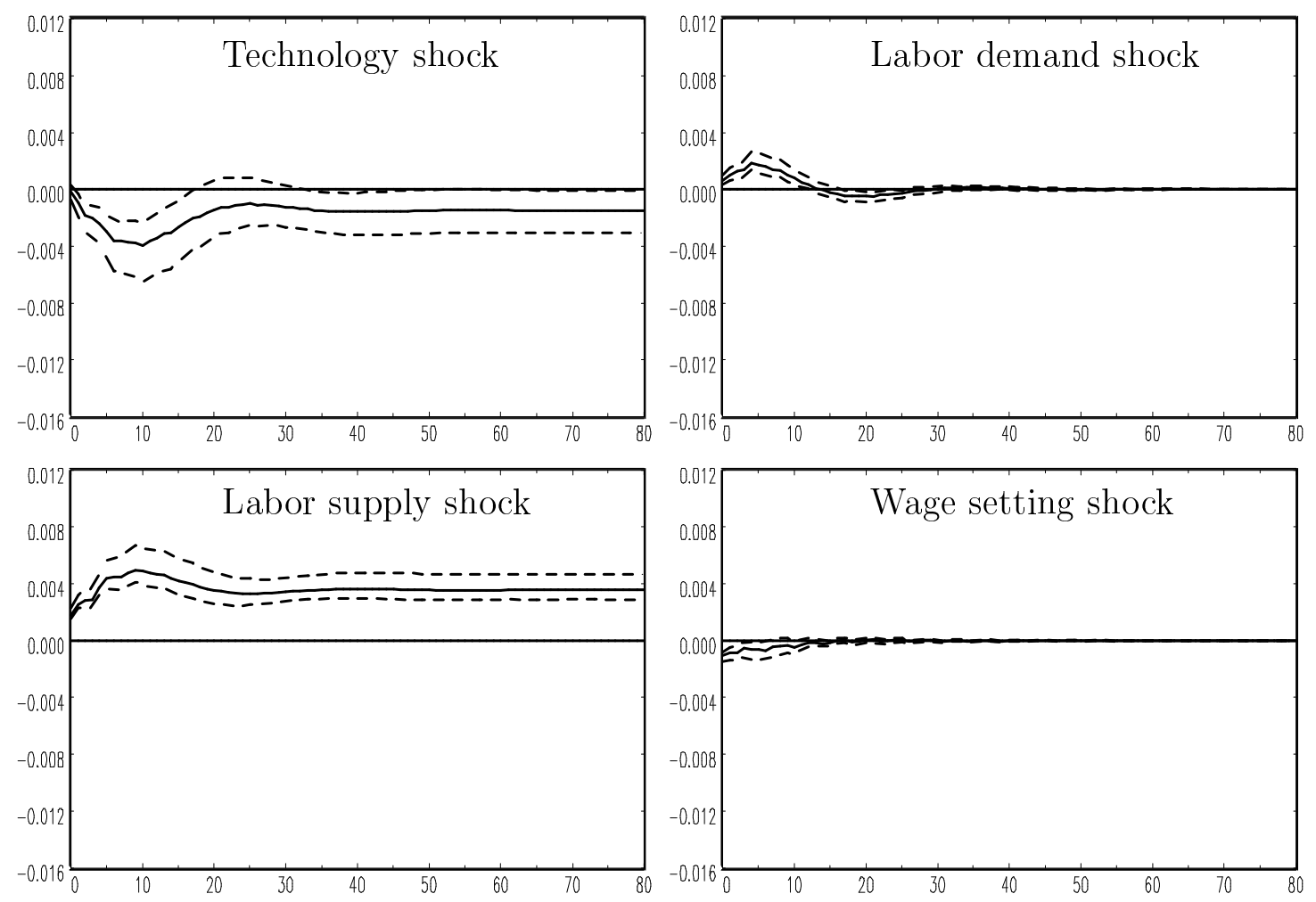

Figure 5. Responses of Unemployment in Subset SVECM, $r=2$ 
Table 6. Forecast Error Variance Decomposition in model with two cointegration vectors

\begin{tabular}{rcccc|cccc}
\hline \hline & \multicolumn{4}{c}{ Full VECM } \\
$h$ & $\varepsilon_{g d p}$ & $\varepsilon_{d}$ & $\varepsilon_{s}$ & $\varepsilon_{w}$ & $\varepsilon_{g d p}$ & $\varepsilon_{d}$ & $\varepsilon_{s}$ & $\varepsilon_{w}$ \\
\hline 1 & 0.043 & 0.107 & 0.697 & 0.152 & 0.005 & 0.084 & 0.694 & 0.217 \\
2 & 0.136 & 0.135 & 0.611 & 0.118 & 0.067 & 0.099 & 0.710 & 0.124 \\
3 & 0.232 & 0.132 & 0.531 & 0.105 & 0.154 & 0.109 & 0.647 & 0.090 \\
4 & 0.306 & 0.127 & 0.485 & 0.082 & 0.200 & 0.115 & 0.619 & 0.066 \\
5 & 0.321 & 0.135 & 0.482 & 0.061 & 0.215 & 0.125 & 0.612 & 0.048 \\
6 & 0.347 & 0.128 & 0.475 & 0.049 & 0.239 & 0.114 & 0.612 & 0.036 \\
7 & 0.374 & 0.119 & 0.462 & 0.045 & 0.273 & 0.102 & 0.595 & 0.030 \\
8 & 0.398 & 0.108 & 0.456 & 0.038 & 0.294 & 0.092 & 0.589 & 0.025 \\
9 & 0.406 & 0.100 & 0.462 & 0.033 & 0.307 & 0.083 & 0.589 & 0.021 \\
10 & 0.416 & 0.090 & 0.465 & 0.029 & 0.315 & 0.074 & 0.594 & 0.018 \\
20 & 0.414 & 0.049 & 0.522 & 0.016 & 0.309 & 0.039 & 0.642 & 0.010 \\
30 & 0.376 & 0.041 & 0.570 & 0.013 & 0.269 & 0.033 & 0.690 & 0.008 \\
40 & 0.353 & 0.034 & 0.603 & 0.011 & 0.247 & 0.027 & 0.720 & 0.006 \\
50 & 0.337 & 0.029 & 0.625 & 0.009 & 0.232 & 0.022 & 0.740 & 0.005 \\
60 & 0.325 & 0.025 & 0.642 & 0.008 & 0.221 & 0.019 & 0.756 & 0.005 \\
70 & 0.316 & 0.022 & 0.655 & 0.007 & 0.212 & 0.017 & 0.767 & 0.004 \\
80 & 0.308 & 0.020 & 0.666 & 0.006 & 0.205 & 0.015 & 0.776 & 0.004 \\
\hline \hline
\end{tabular}

\section{VECM Estimates}

Estimated coefficients of the full VECM and the Subset VECM for the model with one cointegration vector are listed in Table 7 and Table 8 on the following pages. 
Table 7. OLS estimates of Full VECM

\begin{tabular}{|c|c|c|c|c|}
\hline & $\Delta(g d p-e)_{t}$ & $\Delta e_{t}$ & $\Delta u_{t}$ & $\Delta(w-p)_{t}$ \\
\hline$e c_{t-1}$ & $\begin{array}{c}-0.031 \\
(-0.855)\end{array}$ & $\begin{array}{c}0.104 \\
(2.150)\end{array}$ & $\begin{array}{c}-0.022 \\
(-2.819)\end{array}$ & $\begin{array}{c}-0.273 \\
(-4.837)\end{array}$ \\
\hline$\Delta(g d p-e)_{t-1}$ & $\begin{array}{c}-0.124 \\
(-1.095)\end{array}$ & $\begin{array}{c}-0.102 \\
(-0.680)\end{array}$ & $\begin{array}{c}-0.111 \\
(-4.716)\end{array}$ & $\begin{array}{c}-0.252 \\
(-1.445)\end{array}$ \\
\hline$\Delta(g d p-e)_{t-2}$ & $\begin{array}{c}-0.054 \\
(-0.450)\end{array}$ & $\begin{array}{c}-0.163 \\
(-1.035)\end{array}$ & $\begin{array}{c}-0.103 \\
(-4.119)\end{array}$ & $\begin{array}{c}0.109 \\
(0.592)\end{array}$ \\
\hline$\Delta(g d p-e)_{t-3}$ & $\begin{array}{c}-0.115 \\
(-0.986)\end{array}$ & $\begin{array}{c}0.131 \\
(0.846)\end{array}$ & $\begin{array}{c}-0.079 \\
(-3.241)\end{array}$ & $\begin{array}{c}-0.002 \\
(-0.008)\end{array}$ \\
\hline$\Delta(g d p-e)_{t-4}$ & $\begin{array}{c}0.370 \\
(3.367)\end{array}$ & $\begin{array}{c}0.125 \\
(0.861)\end{array}$ & $\begin{array}{c}-0.065 \\
(-2.826)\end{array}$ & $\begin{array}{c}-0.095 \\
(-0.562)\end{array}$ \\
\hline$\Delta e_{t-1}$ & $\begin{array}{c}0.157 \\
(2.096)\end{array}$ & $\begin{array}{c}-0.397 \\
(-4.019)\end{array}$ & $\begin{array}{c}-0.031 \\
(-1.970)\end{array}$ & $\begin{array}{c}0.006 \\
(0.050)\end{array}$ \\
\hline$\Delta e_{t-2}$ & $\begin{array}{c}-0.064 \\
(-0.814)\end{array}$ & $\begin{array}{c}0.014 \\
(0.139)\end{array}$ & $\begin{array}{c}-0.036 \\
(-2.212)\end{array}$ & $\begin{array}{c}-0.136 \\
(-1.123)\end{array}$ \\
\hline$\Delta e_{t-3}$ & $\begin{array}{c}-0.106 \\
(-1.410)\end{array}$ & $\begin{array}{c}0.147 \\
(1.486)\end{array}$ & $\begin{array}{c}-0.021 \\
(-1.343)\end{array}$ & $\begin{array}{c}-0.266 \\
(-2.301)\end{array}$ \\
\hline$\Delta e_{t-4}$ & $\begin{array}{c}0.185 \\
(2.547)\end{array}$ & $\begin{array}{c}0.191 \\
(1.986)\end{array}$ & $\begin{array}{c}0.019 \\
(1.224)\end{array}$ & $\begin{array}{c}0.071 \\
(0.633)\end{array}$ \\
\hline$\Delta u_{t-1}$ & $\begin{array}{c}0.979 \\
(2.341)\end{array}$ & $\begin{array}{l}-1.835 \\
(-3.319)\end{array}$ & $\begin{array}{c}0.299 \\
(3.426)\end{array}$ & $\begin{array}{c}0.791 \\
(1.227)\end{array}$ \\
\hline$\Delta u_{t-2}$ & $\begin{array}{c}-0.513 \\
(-1.168)\end{array}$ & $\begin{array}{c}0.295 \\
(0.509)\end{array}$ & $\begin{array}{c}0.102 \\
(1.117)\end{array}$ & $\begin{array}{c}0.556 \\
(0.822)\end{array}$ \\
\hline$\Delta u_{t-3}$ & $\begin{array}{c}-0.270 \\
(-0.648)\end{array}$ & $\begin{array}{c}0.425 \\
(0.773)\end{array}$ & $\begin{array}{c}-0.107 \\
(-1.228)\end{array}$ & $\begin{array}{l}-1.347 \\
(-2.100)\end{array}$ \\
\hline$\Delta u_{t-4}$ & $\begin{array}{c}0.499 \\
(1.196)\end{array}$ & $\begin{array}{c}-0.294 \\
(-0.533)\end{array}$ & $\begin{array}{c}0.537 \\
(6.166)\end{array}$ & $\begin{array}{c}0.260 \\
(0.404)\end{array}$ \\
\hline$\Delta(w-p)_{t-1}$ & $\begin{array}{c}0.017 \\
(0.267)\end{array}$ & $\begin{array}{c}0.012 \\
(0.147)\end{array}$ & $\begin{array}{c}0.022 \\
(1.649)\end{array}$ & $\begin{array}{l}-0.308 \\
(-3.163)\end{array}$ \\
\hline$\Delta(w-p)_{t-2}$ & $\begin{array}{c}-0.123 \\
(-1.965)\end{array}$ & $\begin{array}{c}0.361 \\
(4.354)\end{array}$ & $\begin{array}{c}0.027 \\
(2.040)\end{array}$ & $\begin{array}{c}-0.702 \\
(-7.264)\end{array}$ \\
\hline$\Delta(w-p)_{t-3}$ & $\begin{array}{c}-0.020 \\
(-0.292)\end{array}$ & $\begin{array}{c}0.129 \\
(1.404)\end{array}$ & $\begin{array}{c}0.007 \\
(0.485)\end{array}$ & $\begin{array}{c}-0.465 \\
(-4.329)\end{array}$ \\
\hline$\Delta(w-p)_{t-4}$ & $\begin{array}{c}0.014 \\
(0.196)\end{array}$ & $\begin{array}{c}0.129 \\
(1.370) \\
\end{array}$ & $\begin{array}{c}0.017 \\
(1.119) \\
\end{array}$ & $\begin{array}{c}0.159 \\
(1.450)\end{array}$ \\
\hline const. & $\begin{array}{c}0.064 \\
(1.223)\end{array}$ & $\begin{array}{c}-0.151 \\
(-2.174)\end{array}$ & $\begin{array}{c}0.032 \\
(2.946)\end{array}$ & $\begin{array}{c}0.441 \\
(5.445)\end{array}$ \\
\hline$s 1$ & $\begin{array}{c}-0.065 \\
(-2.569)\end{array}$ & $\begin{array}{c}0.037 \\
(1.116)\end{array}$ & $\begin{array}{c}0.007 \\
(1.268)\end{array}$ & $\begin{array}{c}-0.138 \\
(-3.558)\end{array}$ \\
\hline$s 2$ & $\begin{array}{c}0.035 \\
(2.212)\end{array}$ & $\begin{array}{l}-0.059 \\
(-2.805)\end{array}$ & $\begin{array}{c}-0.010 \\
(-2.884)\end{array}$ & $\begin{array}{c}0.003 \\
(0.138)\end{array}$ \\
\hline$s 3$ & $\begin{array}{c}-0.031 \\
(-1.128)\end{array}$ & $\begin{array}{c}0.047 \\
(1.311)\end{array}$ & $\begin{array}{c}-0.000 \\
(-0.023)\end{array}$ & $\begin{array}{c}-0.098 \\
(-2.314)\end{array}$ \\
\hline$i 91 q 1$ & $\begin{array}{c}-0.152 \\
(-12.656)\end{array}$ & $\begin{array}{c}0.245 \\
(15.480)\end{array}$ & $\begin{array}{l}-0.006 \\
(-2.573)\end{array}$ & $\begin{array}{l}-0.106 \\
(-5.711)\end{array}$ \\
\hline
\end{tabular}

Note: $t$-ratios in parentheses 
Table 8. EGLS estimates of Subset VECM

\begin{tabular}{|c|c|c|c|c|}
\hline & $\Delta(g d p-e)_{t}$ & $\Delta e_{t}$ & $\Delta u_{t}$ & $\Delta(w-p)_{t}$ \\
\hline$e c_{t-1}$ & & $\begin{array}{c}0.058 \\
(2.311)\end{array}$ & $\begin{array}{c}-0.026 \\
(-4.855)\end{array}$ & $\begin{array}{c}-0.307 \\
(-10.053)\end{array}$ \\
\hline$\Delta(g d p-e)_{t-1}$ & & & $\begin{array}{c}-0.133 \\
(-7.594)\end{array}$ & \\
\hline$\Delta(g d p-e)_{t-2}$ & & & $\begin{array}{l}-0.126 \\
(-6.520)\end{array}$ & \\
\hline$\Delta(g d p-e)_{t-3}$ & & & $\begin{array}{c}-0.055 \\
(-4.702)\end{array}$ & \\
\hline$\Delta(g d p-e)_{t-4}$ & $\begin{array}{c}0.529 \\
(8.731)\end{array}$ & & $\begin{array}{c}-0.068 \\
(-5.918)\end{array}$ & \\
\hline$\Delta e_{t-1}$ & $\begin{array}{c}0.195 \\
(6.515)\end{array}$ & $\begin{array}{c}-0.304 \\
(-7.435)\end{array}$ & $\begin{array}{l}-0.057 \\
(-5.006)\end{array}$ & \\
\hline$\Delta e_{t-2}$ & & & $\begin{array}{c}-0.041 \\
(-3.248)\end{array}$ & $\begin{array}{c}-0.197 \\
(-3.635)\end{array}$ \\
\hline$\Delta e_{t-3}$ & & & & $\begin{array}{c}-0.243 \\
(-4.429)\end{array}$ \\
\hline$\Delta e_{t-4}$ & $\begin{array}{c}0.240 \\
(5.626)\end{array}$ & $\begin{array}{c}0.133 \\
(3.387)\end{array}$ & & \\
\hline$\Delta u_{t-1}$ & $\begin{array}{c}0.722 \\
(2.693)\end{array}$ & $\begin{array}{c}-1.344 \\
(-3.524)\end{array}$ & $\begin{array}{c}0.294 \\
(4.376)\end{array}$ & \\
\hline \multicolumn{5}{|l|}{$\Delta u_{t-2}$} \\
\hline \multicolumn{5}{|l|}{$\Delta u_{t-3}$} \\
\hline$\Delta u_{t-4}$ & & & $\begin{array}{c}0.507 \\
(7.652)\end{array}$ & \\
\hline$\Delta(w-p)_{t-1}$ & & & & $\begin{array}{l}-0.483 \\
(-9.027)\end{array}$ \\
\hline$\Delta(w-p)_{t-2}$ & $\begin{array}{l}-0.111 \\
(-3.968)\end{array}$ & $\begin{array}{l}0.216 \\
(5.686)\end{array}$ & $\begin{array}{l}0.024 \\
(3.507)\end{array}$ & $\begin{array}{c}-0.811 \\
(-15.746)\end{array}$ \\
\hline$\Delta(w-p)_{t-3}$ & & & & $\begin{array}{l}-0.580 \\
(-9.519)\end{array}$ \\
\hline \multicolumn{5}{|l|}{$\Delta(w-p)_{t-4}$} \\
\hline const. & $\begin{array}{c}0.027 \\
(6.922)\end{array}$ & $\begin{array}{c}-0.098 \\
(-2.917)\end{array}$ & $\begin{array}{c}0.041 \\
(5.329)\end{array}$ & $\begin{array}{c}0.478 \\
(12.218)\end{array}$ \\
\hline$s 1$ & $\begin{array}{c}-0.065 \\
(-8.617)\end{array}$ & $\begin{array}{c}0.030 \\
(4.524)\end{array}$ & $\begin{array}{c}0.005 \\
(2.091)\end{array}$ & $\begin{array}{l}-0.117 \\
(-6.347)\end{array}$ \\
\hline$s 2$ & $\begin{array}{c}0.022 \\
(4.818)\end{array}$ & $\begin{array}{c}-0.022 \\
(-3.758)\end{array}$ & $\begin{array}{c}-0.014 \\
(-7.926)\end{array}$ & $\begin{array}{c}0.029 \\
(3.440)\end{array}$ \\
\hline$s 3$ & $\begin{array}{c}-0.050 \\
(-6.183)\end{array}$ & $\begin{array}{c}0.065 \\
(5.811)\end{array}$ & $\begin{array}{c}-0.001 \\
(-0.184)\end{array}$ & $\begin{array}{c}-0.107 \\
(-5.603)\end{array}$ \\
\hline$i 91 q 1$ & $\begin{array}{c}-0.151 \\
(-14.695)\end{array}$ & $\begin{array}{c}0.252 \\
(17.960)\end{array}$ & $\begin{array}{l}-0.007 \\
(-2.906)\end{array}$ & $\begin{array}{c}-0.098 \\
(-5.890)\end{array}$ \\
\hline
\end{tabular}

Note: $t$-ratios in parentheses 